Jaime Torres Bodet.

\title{
LECCION DE COSAS (1)
}

(D)ROSERPINA era una de esas mujeres a quienes, de niñas, nadie pensó contar un cuento de hadas. Dueña de la lámpara de Aladino, no hubiera sabido encender con ella una pipa.

Había, en no sé qué rectitud de sus labios, la confesión de una alarma terrible: no podía pronunciar claramem te la palabra "Simbad». Erudita en todo género de orientalismos, Raquel me descifró su secreto:

-Tranquilícese usted-me dijo-. A Proserpina, si hubiésemos nacido en Constantinopla, podríamos regalar sin peligro el Tapete Mágico. Ya tomaría ella buen cuidado de no viajar en él. Al contrario. Lo enrollaría junto con sus maletas, como un estuche de golf, y lo enviaría a dormir al vagón de los equipajes.

Fíabía un fondo de verdad en aquella malicia. En toda malicia lo hay. Por eso, sorprendida de pronto al volver de la calle, en la escuela, en un rincón de la Biblioteca de Altos Estudios, en una avenida de la Alameda, Proserpina daba invariablemente la impresión de salir de una partitura. De la partitura de una ópera de Gluck. Como la música de Orfeo, su voz-

(1) Capítulo inédito de Muerte de Proserpina, novela en preparación. 
al hablar - estaba alineada a lo largo de un laberinto de insinuaciones abstractas. Pero, si callaba, su silencio era más grave aún. Porque recordaba, en aquellos minutos, ese paisaje filosófico de las telas de Poussin en cuyo ambiente, para sugerir el conjunto de un bosque, los árboles se persiguen, se acercan unos a otros, se agrupan, adquieren en seguida el aspecto de esos sillones que fingen un estrado real en el escaparate de las mueblerías.

Sin embargo, vivíamos en 1919. Estábamos en otoño. Acabábamos de leer el Emilio. Era imposible que doscientos siete años después del nacimiento de Juan Jacobo Rousseau, una mujer del carácter de Proserpina no estuviese aun resignada a "regresar a la Naturaleza».

Le hice los primeros reproches.

- Tus trajes - le dije - no tienen aire de trajes. No pesan. No confiesan nunca de qué color están hechos. Parecen teoremas. Necesitan siempre que los demuestres. $\mathrm{Y}$ tus costumbres son todavía más misteriosas. Hace cuatro meses que somos amigos y no sé aún si te gustan los chocolates, si tuviste una hermana que se llamara Carlota, si prefieres Los espectros a Hedda Gabler, Hedda Gabler a Solness el constructor. En vano llegas todos los días con una raqueta distinta debajo del brazo. Juegas al tennis, lo sé. Pero ¿podrías decirme de qué color estaba el cielo esta mañana, quién tuvo la culpa de que perdieses el séptimo set, en qué momento quisiste que una paloma picase a Alejandro en la esquina del ojo derecho? Cuando llueve, no te sometes nunca a los impermeables. Y si al fin admites el tuyo es, sólo, por no contrariar a los transeúntes. Cierra los ojos. Así. Ciérralos todavía más. Toma este lápiz. Bueno. Ahora, dibuja en tu cuaderno de notas la forma del objeto, del animal o de la persona en que pienses....

¡Naturalmente! En vez de la rosa, de la cruz o del pato que yo esperaba, había dibujado un canguro. 
- ¿Por qué exageras las dificultades de todo lo que te propones? ¿Por qué escribes obscuro, subscripciones, Schehrehzahdah y backaratt, en vez de baccarat, Scherazada, suscripciones y oscuro? ¿Por qué eliges siempre el camino más largo para venir al colegio, el tranvía más pletórico para regresar a tu casa, el barrio más alejado del centro para vivir, el pastel más oculto de la bandeja, el número de la lotería que no llevan nunca las vendedoras, la postura más incómoda para contestar a los drives? Eso es. Acabo de descubrir la palabra que me faltaba. Eres incómoda. Y todo lo que no es incómodo te satisface incompletamente. Ahora comprendo por qué dices que estás extenuada cuando no has hecho sino subir la escalera; por qué afirmas que adoras lo que solamente te gusta; por qué añades que sufres cuando solamente te contrarías. Vas demasiado lejos. De una obra, lo primero que lees es el epílogo. De un helado, lo primero que comes es esa cereza egoísta que los golosos reservan para el final. ¿Y qué es lo que te interesa en el semblante de un hombre? Los ojos, naturalmente, sí. Pero, dentro de los ojos, las pupilas. Y, en las pupilas, el iris. $Y$, en el iris, ese puntito de nácar por donde nos está adivinando siempre todos los pensamientos ocultos la mirada invisible de un dios.... No te incendies. No vayas tan de prisa. Dale un descanso a tu sombra. Supón que a tu ángel de la guarda se le acaba de clavar una espina en el pie. ¿Sonríes? Es mejor que te sientes. Ahora, imagina que soy un maestro de escuela. ¿Quieres que te dé la primera de mis Lecciones de cosas?

Estábamos en un parque. Nos envolvía esa excelente escenografía de otoño que hace pensar en las inmediaciones de aquellos lugares en que deberían representarse los dramas de Shakespeare. Por ejemplo: Un rincón en el bosque. Sale Macbeth, seguido por el fantasma de Banquo. Había tanto verde debajo, encima y alrededor de nosotros que se hacía extremada- 
mente difícil precisar cuál era el último árbol de la naturaleza y cuál la primera rama de la civilización. Del sombrero de paja que Proserpina se había puesto, le escurrían sobre los hombros dos cintas azules, tipográficas y pedantes como un par de comillas. En los ojos, en los brazos, en la sonrisa dudosa, demostraba ese terror de sentarse en el césped que distingue a las palomas de todas las bibliotecas. Se sentía dichosa. Era la primera vez que se oía tratar con rigor.

Para complacerme, escogió una piedra del parque, la más limpia del sitio en que nos habíamos detenido. Se sentó en ella.

\section{- ¿Conoces el árbol que tienes al frente?}

$\mathrm{Me}$ dijo que sí, con un asentimiento imperceptible de la sonrisa.

\section{- ¿Cómo se llama?}

-Es un eucaliptus.

No podía fallar. Sólo a ella se le hubiese ocurrido confundir con un fresno esa cosa terrible-úes, eles y pes-que designaba por medio de una palabra suficientemente difícil para parecerle probable: eucaliptus.

-Estás equivocada-corregí yo-. Es un fresno. Mira: la hoja de los fresnos tiene la forma de una mano enteramente abierta. En sus venas de oro una gitana que supiese al mismo tiempo algo de Historia Natural podría leer el destino de todo el resto del árbol. El número de los pájaros que hayan de formar un nido en sus ramas, el nombre del leñador que echará abajo su tronco, las iniciales que renacerán de su corteza cuando una fábrica de papel artificial lo haya convertido al fin en un pliego de cartas....

Se aburría de arriba abajo, como la lluvia de un arpa. Para inspirarle la idea de una complicidad, le estreché silenciosamente la punta de los dedos. Todo su tacto se había echado a dormir. Quise darme a mí mismo una impresión de confianza. Conté las hojas que habían caído junto a nosotros durante el tiempo que 
había durado nuestra conversación. Veinticuatro. ¡No eran sino veinticuatro! Dentro de veinticuatro díaspensé-Proserpina se decidirá a devolverme mis besos. ¿Pero no habría cometido yo algún error en la cuenta? ¿No se trataría solamente de veinticuatro horas?

Se aburría. En el fondo, era un miembro más de esa generación de señoritas para quienes el mar no es sino un producto de los transatlánticos. $\mathrm{Y}$ sin embargo... . No. No podía ser. El relato de la niñez que había mandado grabar en su disco me prometía un carácter absolutamente distinto. Se lo dije. ¿Cómo podía concebirse una crueldad tan ingenua?

$\mathrm{Me}$ parece estar oyendo su risa. ¿Luego había sido capaz de creer todas las atrocidades de que se había acusado en el disco? ¡Qué malignidad! Y ella que lo quería distribuir para impresionar exclusivamente a los tontos. Si aquello no tenía nada de cierto. Si nadie recuerda nunca un episodio real de su infancia. $\mathrm{Ni}$ los autores que la describen con todo detalle en sus memorias.

¿A quién creer? ¿A la pequeña Proserpina coronada de un sombrero de paja cubierto de uvas? ¿A la invisible sibila de los fonógrafos Víctor? Se hacía noche. El aire llegaba tan pausadamente a nosotros que, al respirarlo, hubiéramos podido contar las secciones de los diferentes perfumes de que venía tejido. Perfume de los claveles, encendido y espeso como el sueño que produce un narcótico. Perfume de la hoja de los duraznos, entristecido por el remordimiento de no entregarse todo a la fruta vecina. Perfume de las violetas, discreto como la primera sonrisa de una viuda en un baile de máscaras. Perfume de los geranios silvestres, asoleado y redondo a pesar de la sombra, como el anillo de una plaza de toros, en una aldea española, el día en que el alcalde celebra su santo. Y por último, ruiseñor silencioso de los olores, perfume del jazmín. Perfume tan penetrante, tan alejado de todos, 
que el más delicado poeta no querría compararlo sino al perfume de otro jazmín.

¿Cuánto hubiese deseado explicar a Proserpina todas aquellas concordancias de los sentidos! Pero no supe. En la sombra, el temor de parecerle ridículo me hubiese hecho tartamudear. También las palabras, también las palabras, son teclas que no puedo tocar de noche, a ciegas, de prisa, con la elegancia de una dactilógrafa.

Salió la luna. Se humedecieron los grillos. Proserpina propuso el regreso. La ciudad la atraía visiblemente, con el imán de sus conferencias, de sus conciertos, de sus cursos nocturnos, de sus lecturas al pie de la lámpara. Era, definitivamente, una mujer vencida por la civilización.

- No hay paisaje, por hermoso que sea, que no pueda caber en una frase feliz.

Lo dijo gravemente, como si lo hubiese leído en la vidriera de un hotel de 1824, en Nápoles, sobre la boca indecisa de Madame de Staél.

Sentí celos de una vocación tan perfecta. Quise avergonzarla con el recuerdo de alguna cosa que no fuese estrictamente suya, de una noticia, de un dato, de una noción del mundo en que yo mismo hubiese participado.

\section{Le supliqué:}

- Proserpina, por favor, antes de tomar el tranvía, dígame ¿cómo se llama el árbol que tiene en este momento a su izquierda?

$\mathrm{La}$ omisión del tuteo le hizo advertir mi disgusto. Procuró ser amable.

-Es un fresno.

¿Sería verdad?... Me acerqué. Examiné detenidamente su tronco, para estar seguro, más tarde, de no haber soñado. Era un eucaliptus. De todos modos, la clase no había sido superflua. Proserpina había aprendido a cambiar de opinión. 